\title{
COMBINATION OF ATTACHMENT PATTERNS IN ROMANTIC RELATIONSHIP AND ITS QUALITY
}

\author{
Dariusz Kuncewicz ${ }^{1}, \&$ Dorota Kuncewicz ${ }^{2}$ \\ ${ }^{1}$ Department of Clinical Psychology, University of Social Sciences and Humanities (Poland) \\ ${ }^{2}$ Department of Psychology, The John Paul II Catholic University of Lublin (Poland)
}

\begin{abstract}
The aim of this study was to explore the connection between a combination of attachment patterns in a couple and their relationship`s quality. The study involved 200 heterosexual couples $(N=400)$, aged 21 to 45 with the relationship's length from 0,5 to 25 years. We used Experiences in Close Relationships questionnaire and cluster analysis ( $k$-means procedure) to isolate three main attachment patterns: secure, anxious, avoidant. We also referred to Couple Satisfaction Index-32 and Partnership Questionnaire to measure different aspects of a relationship`s quality: satisfaction, quarreling, tenderness and mutual communication. The key results of the comparisons between couples, isolated on the basis of a combination of attachment patterns showed that: (1) a combination of two secure patterns was the most while a combination of anxious-avoidant and two avoidant patterns the least beneficial to a relationship`s quality; (2) a combination of secure and insecure patterns turned out to be more favourable than a combination of two insecure ones; (3) a configuration of two anxious patterns appeared to be partly beneficial and partly detrimental; (4) a combination of a man with a secure and a woman with an insecure pattern would be more advantageous than a "reversed" combination of a man with an insecure pattern and a woman with a secure pattern.
\end{abstract}

Keywords: Romantic relationship, combination of attachment patterns, self-report measures.

\section{Introduction}

The aim of the study was to check the connection between a combination of attachment patterns in a relationship and its quality. The results of the previous research consistently indicate that a combination of secure attachment patterns favours getting more satisfaction from a relationship than a combination of insecure ones (e.g., Banse, 2004, MacLean, 2002). There is, however, a disagreement over a combination of secure and insecure patterns. The results of some research show that in such a configuration relationship satisfaction is on a level similar to two insecure patterns while other findings suggest the buffering effect of a secure pattern (for a review of the research - see. Mikulincer \& Shaver, 2007). So far the researchers have rarely differentiated one type of insecure pattern from another; nor have they tried a multifaceted approach to a relationship`s quality (they have mainly checked satisfaction in a relationship).

In our study we wanted to check the connection between a combination of attachment patterns in a relationship and its quality in a more comprehensive way. We considered various types of insecure patterns, gender and different dimensions of a relationship`s quality.

\section{Method}

The study involved 200 heterosexual couples $(N=400)$, aged 21 to $45(M=29,37 ; S D=5,35)$ with the relationship's length from 0,5 to 25 years $(M=6,23 ; S D=5,05)$. We used three questionnaires: (1) Experiences in Close Relationships (Brennan, Clark \& Shaver, 1998), including the Anxiety and Avoidance scales (Min = 1, Max = 7); (2) Couple Satisfaction Index-32 (Funk i Rogge, 2007), designed to measure the intensity of Satisfaction in a relationship (Min $=0 ;$ Max $=5)$, and (3) Partnership Questionnaire (Hahlweg, 1996): including the Quarreling, Tenderness and Mutual communication scales $(\operatorname{Min}=0, \operatorname{Max}=3)$. 


\section{Results}

Cluster analysis ( $k$-means procedure) was performed using the two dimensions, Anxiety and Avoidance of the ECR questionnaire to isolate three main attachment patterns in a group of women and men. In both gender groups, low scores on the Anxiety $(M=3.11,2.57)$ and low on the Avoidance scale $(M=1.71,1.81)$ constituted a secure pattern (in 102 women and 91 men); high scores on the Anxiety $(M=4.83 ; 4.33)$ and low on the Avoidance scale $(M=1.83 ; 1.81)$ - an anxious pattern (in 74 women and 80 men $)$; high on the Avoidance $(\mathrm{M}=3.58 ; 3.44)$ and average on the Anxiety scale $(M=3.88 ; 3.02)-$ an avoidant pattern (in 24 women and 29 men).

Next, we isolated six types of couples, on the basis of a combination of attachment patterns in a relationship, and six subtypes, additionally including the partner's sex (Table 1).

Table 1. Types and subtypes of couples isolated on the basis of a combination of attachment patterns in a relationship.

\begin{tabular}{|c|c|c|c|}
\hline $\begin{array}{l}\text { Type and subtype } \\
\text { of a couple }\end{array}$ & $\begin{array}{l}\text { a combination of attachment patterns } \\
\text { in a relationship }\end{array}$ & $N$ & $\%$ \\
\hline I & secure-secure & 52 & 26 \\
\hline II & secure-anxious & 65 & 32,5 \\
\hline IIa & secure (female)-anxious (male) & 36 & 18 \\
\hline Illb & anxious (female)-secure (male) & 29 & 14,5 \\
\hline III & secure-avoidant & 24 & 15,5 \\
\hline IIIa & secure (female)-avoidant (male) & 17 & 8,5 \\
\hline IIIlb & avoidant (female)-secure (male) & 7 & 7 \\
\hline IV & anxious-anxious & 33 & 16,5 \\
\hline V & anxious-avoidant & 22 & 11 \\
\hline Va & anxious (female)-avoidant (male) & 11 & 5,5 \\
\hline $\mathrm{Vb}$ & avoidant (female)-anxious (male) & 11 & 5,5 \\
\hline VI & avoidant-avoidant & 4 & 2 \\
\hline
\end{tabular}

In order to check whether there is a connection between a type of a couple and different dimensions of their relationship`s quality, the one-way ANOVAs between subjects were conducted. To maintain the optimal size of compared groups, we excluded Type VI (avoidant-avoidant) from our calculations, and randomly selected 30 people from Type I (secure-secure) and Type II (secure-anxious).We found significant effects of a couple's type in all four dimensions of their relationship`s quality (see Figure 1).

Figure 1. Average intensity of different dimensions of a relationship`s quality versus a type of couples isolated on the basis of a combination of attachment patterns (I, II, III, IV, V, VI).

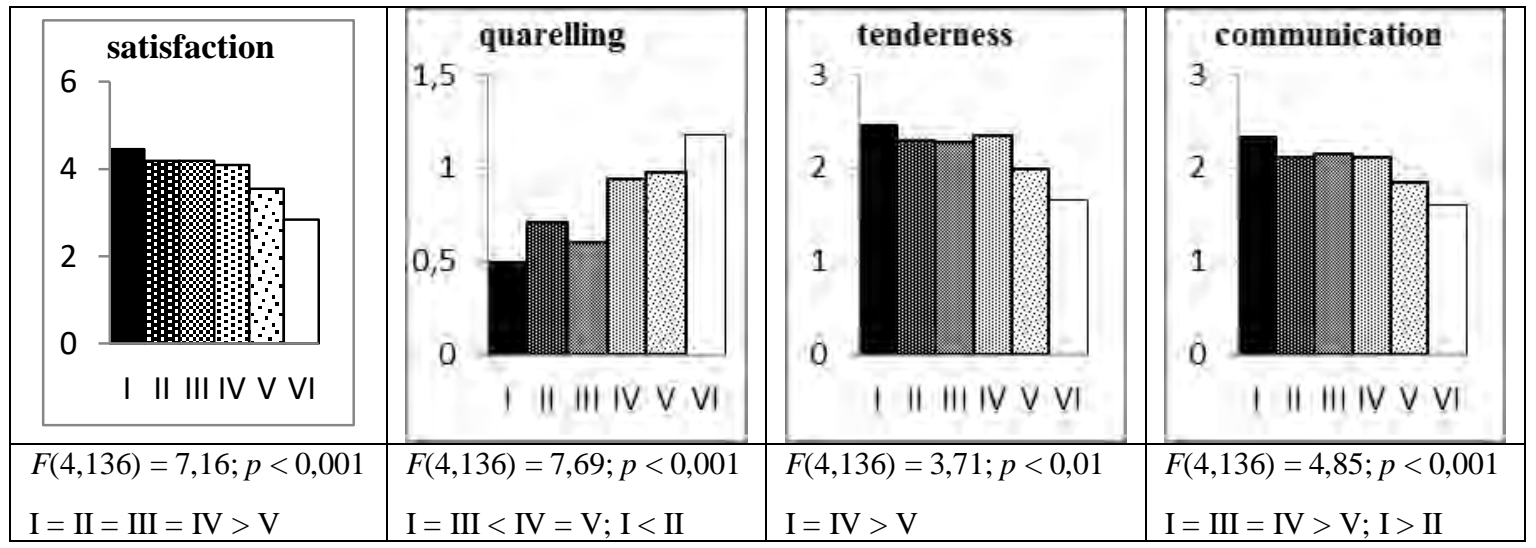

Post hoc comparison, using the Tukey HSD (the signs ">", "<" symbolize the significance and direction of differences between the average dimensions of a relationship`s quality at least on the $p<0.05$ level; the sign "=": lack of significant differences), indicated that a combination of secure-secure patterns (I) turned out to be the most beneficial for all dimensions of a relationship`s quality, and a combination of anxious-avoidant patterns (V) proved the least advantageous. The couples assigned to the avoidant-avoidant type (VI), excluded from post hoc pair comparison, scored the lowest average in all dimensions of a relationship`s quality. 
The buffering effect of a secure pattern took place. A combination of secure-avoidant patterns (III) coexisted with satisfaction in a relationship, negative behavior during quarrels, and mutual communication at a level similar to that which occurred in a combination of secure-secure patterns (I), but higher than the anxious-avoidant (V) [and the avoidant-avoidant type (VI)]. An analogous effect happened in a combination of secure-anxious patterns (II), but only in terms of relationship satisfaction.

A combination of two anxious patterns seems to be partly beneficial and partly detrimental to the quality of a relationship. The anxious-anxious combination (IV) was accompanied by relationship satisfaction, intimacy, and mutual communication at a level similar to that which occurred in the secure-secure combination, and higher than in the avoidant-anxious (V) [and the avoidant-avoidant type (VI)]. In turn, the anxious-anxious combination (IV) had a detrimental effect only in the case of negative behavior during quarrels. Its level was higher than in the secure-secure type and similar to that in the anxious-avoidant combination (V).

We observed that a person`s gender had an effect in the secure-avoidant (III) and secure-anxious (II) combinations. The arrangement in which the man presented a secure and the woman an avoidant pattern (IIIb) was characterized by less negative behaviour during quarrels and more intimacy than the reverse situation (IIIa), in which the woman displayed a secure and the man an avoidant pattern ( $U=25.50, p<0.05 ; U=24.00, p<0.05$ respectively). Similarly, the arrangement which involved a man with a secure pattern and a woman with an anxious one (IIb) was marked by less negative behaviour in quarrels than the opposite one (IIa), formed by a woman with a security and a man with an anxious pattern $[t(63)=1.97 ; p<0.05 ; d$ Cohen $=0.48]$. Gender effect did not occur in the anxious-avoidant combination.

\section{Discussion}

The research results which indicate that secure patterns are the most beneficial for the relationship while insecure and especially avoidant ones are the least - are consistent with previous findings (for a review of the research - see: Mikulincer and Shaver, 2007).

What is more puzzling is the specificity of a combination of two anxious patterns. As demonstrated by the obtained results, during quarrels anxious partners can hurt each other more deeply and frequently than those with secure patterns. The former, however, equal the latter in the overall assessment of satisfaction in their relationships; reciprocity in communicating their own thoughts and feelings, agreeing on plans, and discussing everyday matters (see Hahlweg, 1996); even in experiencing intimacy. By living in fear of being rejected, anxious couples may make life really difficult for each other (see Feeney, 2003), yet - at a more fundamental level - they share it and manifest how much they care about each other.

Gender effect can be accounted for by the unabated attraction of a traditional division of gender roles, according to which it is the man who provides stronger support for the woman than vice versa.

\section{References}

Banse, R. (2004). Adult attachment and marital satisfaction: Evidence for dyadic configuration effects. Journal of Social and Personal Relationships, 21, 273-282.

MacLean, A. P. (2002). Attachment in marriage: Predicting marital satisfaction from partner matching using a three-group typology of adult attachment style. Dissertation Abstracts International: Section B, 63(2-B) (UMI No. AAI3043755)

Brennan, K. A., Clark, C. L., \& Shaver, P. R. (1998). Self-report measurement of adult romantic attachment: An integrative overview. In J. A. Simpson \& W. S. Rholes (Eds.), Attachment theory and close relationships (pp. 46-76). New York: Guilford Press.

Funk, J. L., \& Rogge, R. D. (2007). Testing the Ruler with Item Response Theory: Increasing Precision of Measurement for Relationship Satisfaction with the Couples Satisfaction Index. Journal of Family Psychology, 21, 572-583.

Hahlweg, K. (1996). Fragebogen zur Partnerschaftsdiagnostik (FPD). Göttingen-Bern-Toronto-Seattle: Hogrefe, Verlag für Psychologie.

Mikulincer, M., \& Shaver, P. R. (2007). Attachment in adulthood: Structure, dynamics, and change. New York: Guilford Press.

Feeney, J. A. (2003). The systemic nature of couple relationships: An attachment perspective. In P. Erdman \& T. Caffery (Eds.), Attachment and family systems: Conceptual, empirical, and therapeutic relatedness (pp. 139-164). New York: Brunner-Routledge. 